\title{
Waterflood oil recovery from mixed-wet limestone: dependence on contact angle
}

\author{
Magali Christensen and Yukie Tanino* \\ School of Engineering, University of Aberdeen, AB24 3UE United Kingdom \\ E-mail: ytanino@abdn.ac.uk
}

\begin{abstract}
Remaining oil saturation established by waterflooding from maximum initial oil saturation was measured in Indiana limestone under four mixed-wet conditions established using different organic acids. The altered wettability is characterized by the advancing contact angle of the aqueous phase on a calcite substrate submerged in the oil phase, which ranged from $\theta_{\mathrm{o}}=50^{\circ}$ to $150^{\circ}$. Remaining oil saturation decayed as a power of time for up to 55 pore volumes of water injected, then reached a constant value. The duration of oil production increased linearly with $\theta_{\mathrm{o}}$. In contrast, remaining oil saturation decreased and then increased with increasing $\theta_{0}$ within the range of experimental conditions, with optimal wettability for recovery shifting from $\theta_{\mathrm{o}}=110^{\circ}$ to $135^{\circ}$ as waterflood progressed.
\end{abstract}

\section{Introduction}

Under typical field conditions, flow through an oil reservoir during production is predominantly capillarity-dominated two-phase flow, ${ }^{1}$ and the rate and ultimate volume of oil recovery are largely controlled by the pore geometry, properties of the fluids and the flow, and the wettability of the reservoir rock. Pore geometry and flow velocity are not easily altered. In contrast, all standard techniques for enhanced oil recovery (EOR) alter to some extent the interfacial tension between the fluids and the reservoir wettability by, e.g., altering the tempera- ture (thermal EOR) or by altering the composition of the fluids in the system (polymer floods). In particular, wettability alteration is regarded as the primary mechanism for EOR by smart waterfloods, whereby the chemical composition of the injected water is tuned to optimize recovery, ${ }^{2-6}$ and surfactant floods. ${ }^{7,8}$ Good physical understanding of the dependence of oil recovery on reservoir wettability is essential for optimizing the performance of EOR schemes.

Wettability is commonly characterized by the contact angle between the grain surface, oil, and water. Because wettability depends on mineralogy, ${ }^{9-12}$ oil composition, ${ }^{13-15}$ formation water chemistry, ${ }^{16}$ and reservoir temperature, ${ }^{13,17}$ the contact angle can take on any value from $0^{\circ}$ (strongly hydrophilic or 'water-wetting') to $180^{\circ}$ (strongly hydrophobic or 'oil-wetting'). Furthermore, the contact angle is expected to vary at the pore scale and sub-pore scale due to differential adsorption from crude oil. ${ }^{18-20}$ During oil charge, oil is the non-wetting phase and preferentially flows through the center of the larger pores, while connate water remains in the corners of pores and in the smaller pores. Over time, surface-active components in the oil render the surfaces of grains in direct contact with the oil oil-wetting, while the remaining surfaces remain water-wet. As a result, wettability of the grain surface varies between pores that are invaded by oil (i.e., the larger pores) and those that are not, and within each oil-invaded pore; the system is said to be mixed wet. In this paper, the system wettability is characterized by the contact angle of the oil-contacted grain sur- 
face, $\theta_{\mathrm{o}}$, with $\theta_{\mathrm{o}}$ defined through the aqueous phase.

Dominant characteristics of waterflood oil recovery in uniformly strongly water-wet systems and mixed-wet systems comprising strongly water-wet and strong oil-wet grain surfaces are well established. Under the former, oil recovery ceases after $\tilde{t}=1$ to 2 , where $\tilde{t}$ is the time since the onset of waterflood in terms of the cumulative pore volumes (pv) of flood water injected. ${ }^{21-23}$ In contrast, under mixed-wet conditions, waterflooding has been observed to displace oil even after $\widetilde{t}=O(100$ to 1000$) ;^{21,24}$ this prolonged recovery is attributed to the oil remaining connected within the rock in the form of thin films on the grain surface even at low saturations. ${ }^{21,25}$

However, there is no consensus on the transition between these limits and the optimal wettability for recovery. Laboratory investigations of secondary waterflood recovery as a function of $\theta_{\mathrm{o}}$ under unambiguous and welldefined mixed-wet conditions are, surprisingly, very scarce; this is exacerbated by the sensitivity of two-phase flow behaviour to the oil saturation in the rock when it was rendered mixed wet. ${ }^{21,24,26,27}$ Furthermore, previous studies have reported contradictory $\theta_{\mathrm{o}}$ dependence. According to the aforementioned conceptual framework, $\theta_{0}$ influences oil recovery by controlling the pore-scale and sub-pore scale distribution of the fluids, which in turn suggests a sharp transition in flow behaviour at some critical $\theta_{\mathrm{o}} \approx 90^{\circ}$. Indeed, some pore network simulators predict waterflood relative permeabilities, and hence oil recovery, to be independent of wettability above $\theta_{\mathrm{o}}>90^{\circ} .{ }^{28}$ In contrast, other pore network simulations ${ }^{29,30}$ and laboratory measurements on geological porous media $^{15,27,31,32}$ suggest a gradual, continuous change over the full range of $\theta_{\mathrm{o}}$.

Furthermore, contradictory trends are observed even amongst studies that report a continuous transition between regimes. For example, some studies report maximum recovery at near-neutral wettability, e.g., $\theta_{\mathrm{o}}=100^{\circ}$ for powdered dolomite ${ }^{15}$ and roughly $90^{\circ}$ for consolidated silica sand. ${ }^{31}$ In contrast, recovery from Torpedo sandstone increased mono- tonically from $\theta_{\mathrm{O}}=50^{\circ}$ to $180^{\circ} .^{32}$

This paper presents laboratory measurements of waterflood oil recovery from Indiana limestone, under mixed-wet conditions, for contact angles of oil-contacted grain surfaces ranging from $\theta_{\mathrm{o}}=50^{\circ}$ to $150^{\circ}$; the different mixedwet conditions were established during primary drainage by tuning the acid content of the test oil. Coefficients for an empirical model for the evolution of the remaining oil saturation during a waterflood are determined for each $\theta_{\mathrm{o}}$. The $\theta_{\mathrm{o}}$ dependence of residual oil saturation and the volume of water required to reach residual state are discussed. The results are compared with laboratory measurements by Owens and Archer $^{32}$ and Morrow et al. ${ }^{15}$.

\section{Materials and methods}

\section{Rock}

Indiana limestone, a naturally water-wet rock that is $99.0 \%$ calcite and $1.0 \%$ quartz, ${ }^{24}$ was used as the porous medium. Our samples were homogeneous at the core $(\mathrm{cm})$ scale, and had a mean porosity of $0.150 \pm 0.006$ (standard deviation, 9 samples) and a mean permeability of $k=(6.5 \pm 2.7) \times 10^{-15} \mathrm{~m}^{2}$ (10 samples). Samples were cleaned by hot Soxhlet extraction with a mixture of methanol and toluene prior to use.

\section{Mercury injection/withdrawal cap- illary pressure-saturation}

Capillary pressure-saturation curves for the rock under its natural, water-wet state were measured by mercury injection and withdrawal (Autopore IV 9500, Micromeritics Instrument Corp.). In brief, mercury was injected into an evacuated sample at a constant pressure, $P_{\mathrm{c}, \mathrm{Hg}}$, that was increased in discrete intervals until the sample was fully saturated, then expelled by reducing the pressure in discrete intervals. The volume of mercury that was present in the rock at each pressure was monitored.

A measure of the pore size distribution can be extracted from the mercury injection data. 


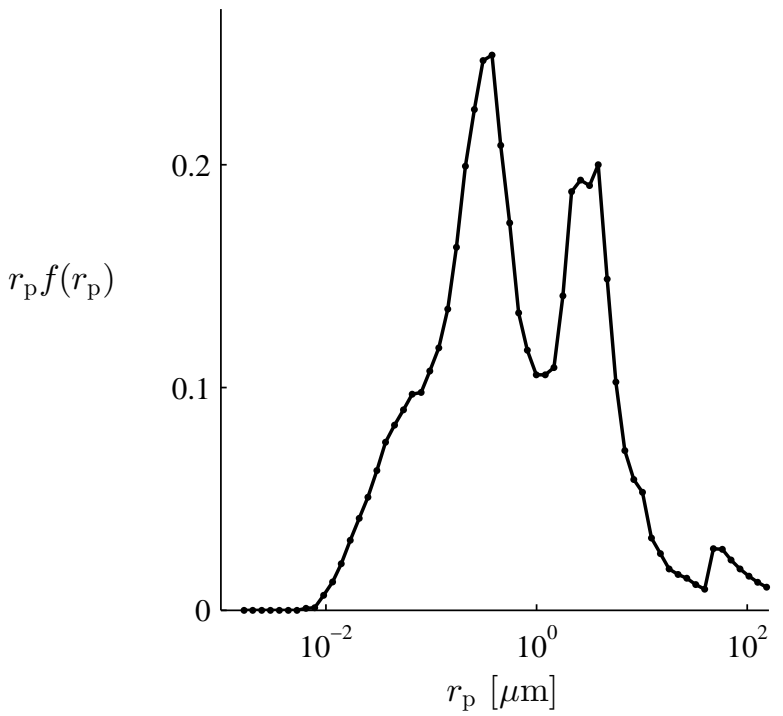

Figure 1: The radius-weighted pore entry size distribution of Indiana limestone.

The smallest pore size that may be invaded by a non-wetting phase at a particular capillary pressure is represented by the equivalent pore throat radii as calculated by the YoungLaplace equation, $r_{\mathrm{p}}=2 \sigma_{\mathrm{Hg}}\left|\cos \theta_{\mathrm{Hg}}\right| / P_{\mathrm{c}, \mathrm{Hg}}$, where $\theta_{\mathrm{Hg}}=135^{\circ}$ is the contact angle of mercury $^{33-35}$ and $\sigma_{\mathrm{Hg}}=485 \mathrm{mN} / \mathrm{m}$ is the interfacial tension between mercury and its vapour. ${ }^{34}$ The pore entry size distribution is then given by $f\left(r_{\mathrm{p}}\right)=\mathrm{d} S_{\mathrm{w}} / \mathrm{d} r_{\mathrm{p}}$, where $S_{\mathrm{w}}$ is the fractional volume of the pore space occupied by the wetting phase (vapour for mercury/vapour). Pore entry sizes were found to span four orders of magnitude, with distinct peaks at $r_{\mathrm{p}}=376 \mathrm{~nm}$ and $3.8 \mu \mathrm{m}$ (Fig. 1).* The minimum pore throat radius that can be measured by the instrument is $r_{\mathrm{p}}=1.7 \mathrm{~nm}$, which is $25 \%$ of the smallest pore throat radius detected in the present sample.

\section{Aqueous and non-aqueous phases}

Five oil phases were considered: $n$-decane (Sigma-Aldrich, $\geq 99 \%$ ), and $6.6 \times 10^{-2} \mathrm{M}$ solutions of cyclohexanecarboxylic acid (SigmaAldrich, 98\%), cyclohexanepropionic acid

${ }^{*}$ A significant portion of the pore space falls below the typical voxel size of commercial X-ray microcomputed tomography scans. Accordingly, the extraction of a representative pore network for this rock remains a challenge. ${ }^{23}$
(99\%), cyclohexanebutyric acid (99\%), and cyclohexanepentanoic acid (98\%) in $n$-decane. This set of organic acids have different alkyl chain lengths and have previously ${ }^{14}$ been shown to render calcite oil-wetting to different degrees.

Table 1: The viscosity of the fluids at $22^{\circ} \mathrm{C}$.

\begin{tabular}{ll}
\hline \hline phase & $\begin{array}{l}\text { viscosity } \\
{[\mathrm{mPa} \mathrm{s}]}\end{array}$ \\
\hline brine & 1.087 \\
\hline$n$-decane & 0.866 \\
\hline $\begin{array}{l}6.6 \times 10^{-2} \mathrm{M} \\
\text { boxylic acid }\end{array}$ & 0.880 \\
\hline $\begin{array}{l}6.6 \times 10^{-2} \mathrm{M} \text { cyclohexanepropi- } \\
\text { onic acid }\end{array}$ & 0.910 \\
\hline $\begin{array}{l}6.6 \times 10^{-2} \mathrm{M} \text { cyclohexanebu- } \\
\text { tyric acid }\end{array}$ & 0.885 \\
\hline $\begin{array}{l}6.6 \times 10^{-2} \mathrm{M} \text { cyclohexanepen- } \\
\text { tanoic acid }\end{array}$ & 0.896 \\
\hline \hline
\end{tabular}

The model connate water and flood water was an aqueous solution of 5 wt. $\% \mathrm{NaCl}$ and 1 wt.\% $\mathrm{KCl}$ saturated with limestone in all experiments.

The dynamic viscosities of all test fluids are presented in Table 1. In particular, the viscosity of the test oil was smaller than that of the brine for all waterfloods considered presently and, accordingly, we do not anticipate that significant viscous fingering took place. The total acid number of each oil was measured using a colour-indicator titration method [ASTM D974-12] and is reported in Table S1 (supplementary information). The interfacial tension between the brine and each oil phase, $\sigma$, and their advancing contact angle, $\theta_{\mathrm{o}}$, on a polished calcite substrate were measured using the pendant drop and sessile drop methods, respectively (OCA 20, Dataphysics); numerical values of $\theta_{\mathrm{o}}$ are summarized in Table S2. Details of the protocols are also provided in the supporting information.

\section{Coreflood setup}

Waterflood oil recovery was measured on twelve cylindrical rock samples ('cores') of length $L=$ $89.0 \pm 0.3 \mathrm{~mm}$ and diameter $37.64 \pm 0.04 \mathrm{~mm}$. 
The samples were housed in custom-made, horizontal Hassler-type pressure cells. Radial confining pressure was applied to prevent bypass of fluids during injection. Test fluids were injected using high-precision syringe pumps (Teledyne ISCO 1000D), and the pressure at the upstream and downstream ends of the core were logged every two minutes throughout the experiment (PDCR 5011 or PDCR 4010, Druck).

\section{Coreflood procedure}

Each coreflood experiment consisted of a sequence of three fluid displacements, as described below, that mimic those associated with secondary oil production. Details of specific steps are described elsewhere, ${ }^{23,24}$ and are thus omitted here.

First, the cores were alternately evacuated and flushed with $\mathrm{CO}_{2}$, then flushed with degassed brine to establish $100 \%$ water saturation representative of the initial state of reservoirs. The pore volume was determined from the difference in the mass of the core between its dry state prior to the experiment and its brine-saturated state.

Next, the test oil was injected at constant pressure from one end to mimic buoyancydriven oil migration into geological reservoirs. A hydrophilic porous plate (Weatherford Laboratories, Stavanger; Ergotech Ltd., Conwy) immediately downstream of the core, with pores much smaller than those of the rock, retained the oil phase inside the core while allowing brine through. After equilibrium was established, viz. flow ceased, the core was removed from the Hassler cell and weighed, and initial oil saturation $S_{\text {oi }}$ was determined by mass balance. In the present study the injection pressure was preselected to achieve $S_{\mathrm{oi}} \approx 0.9$. The duration of primary drainage ranged from 28 to 81 days; our contact angle measurements suggest that this duration is an order of magnitude longer than the time scale over which the oil alters the wettability of the grain surface within the cores (Fig. S1).

In the final step, the brine was injected at constant flow rate to represent waterflooding of an oil reservoir. The core was weighed at selected times to determine the remaining oil saturation. Previous corefloods demonstrate that experimental uncertainty associated with this approach is one saturation $\%{ }^{23}$ the present data corroborate this. The injection rate corresponded to a Darcy velocity of $u_{\mathrm{w}}=30 \mu \mathrm{m} / \mathrm{s}$ in one experiment (coreflood Y, cf. Table 2) and $u_{\mathrm{w}}=1.5$ or $3.0 \mu \mathrm{m} / \mathrm{s}$ in all others. The corresponding macroscopic capillary numbers range between $\mathrm{Ca}=0.15$ and 6.3 (Table S3), where

$$
\mathrm{Ca}=\frac{\mu_{\mathrm{w}} u_{\mathrm{w}} L / k}{P_{\mathrm{b}}},
$$

$P_{\mathrm{b}}=2 \sigma \cos \theta_{\mathrm{o}} / r_{\mathrm{p}, \mathrm{b}}, \mu_{\mathrm{w}}$ is the brine viscosity, and $\left(S_{\mathrm{w}}, r_{\mathrm{p}, \mathrm{b}}\right)=(0.49,0.55 \mu \mathrm{m})$ corresponds to the inflection point in the mercury injection capillary pressure curve. Laboratory measurements by Tanino et al. ${ }^{37}$ and in the present study (see Table 2) indicate that oil recovery is not a strong function of $u_{\mathrm{w}}$ within this range.

\section{Results}

\section{Advancing contact angle}

The capacity of the organic acids to alter wettability is readily apparent by comparing the shapes taken on by drops of brine dispensed on calcite substrates exposed to the different test oils. Brine spreads on calcite submerged in pure $n$-decane, indicative of a strongly waterwet state (Fig. 2a). In contrast, the brine takes on a more circular profile, indicative of oil-wet surfaces, on substrates exposed to oils containing organic acids (e.g., Fig. 2b, c).

For all oil/brine combinations, the contact angle increased with the duration of contact between the substrate and the oil until equilibrium was attained (e.g., Fig. S1). The time required to reach equilibrium was approximately $50 \mathrm{~h}$ for all oils; this duration is comparable to equilibration times reported in literature for NAPL/aqueous phase/mineral contact angle measurements. ${ }^{7,19}$ In this paper, the average contact angle after $60 \mathrm{~h}$ will be taken as $\theta_{\mathrm{o}}$.

The five oils considered presently yield contact angles between $\theta_{\mathrm{o}}=54^{\circ} \pm 7^{\circ}$ and $150^{\circ} \pm$ $0.6^{\circ}$, with $\theta_{\mathrm{o}}$ increasing with increasing alkyl 
(a)

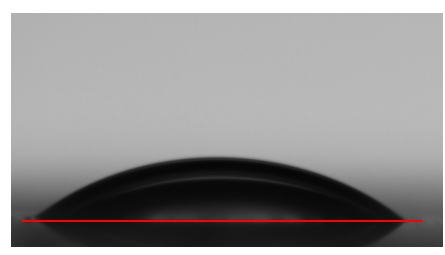

(b)

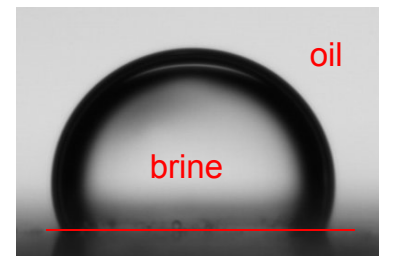

(c)

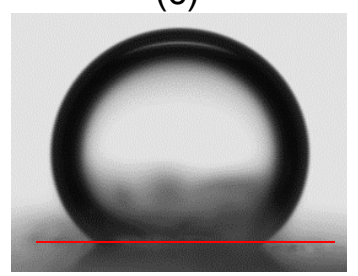

Figure 2: Brine drops on calcite substrate submerged in selected test oils: (a) pure $n$-decane, (b) $6.6 \times 10^{-2} \mathrm{M}$ cyclohexanepropionic acid, and (c) $6.6 \times 10^{-2} \mathrm{M}$ cyclohexanepentanoic acid. Substrate surface is demarcated by the horizontal lines.

chain length of the organic acid in the oil phase (Table S2). In contrast, interfacial tension decreases with increasing alkyl chain length of the organic acid, from $\sigma=52.88 \pm 0.08 \mathrm{mN} / \mathrm{m}$ for pure $n$-decane to $16.46 \pm 0.03 \mathrm{mN} / \mathrm{m}$ for $6.6 \times$ $10^{-2} \mathrm{M}$ cyclohexanepentanoic acid. Combined, $\theta_{\mathrm{o}}$ decreases $\left(\cos \theta_{\mathrm{o}}\right.$ increases) with increasing $\sigma$ (Fig. 3), a trend which has been reported previously for other combinations of NAPL/aqueous solution/mineral substrates. ${ }^{15,38}$

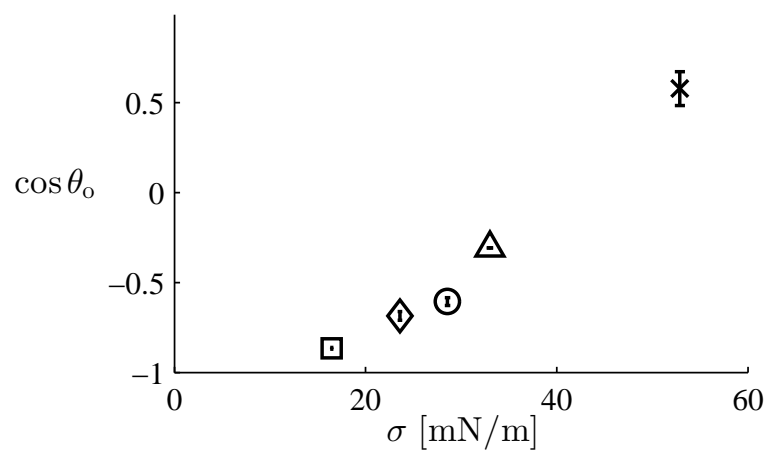

Figure 3: Correlation between advancing contact angle and interfacial tension for $n$-decane $(\times)$ and $6.6 \times 10^{-2} \mathrm{M}$ cyclohexanecarboxylic acid (triangle), cyclohexanepropionic acid (circle), cyclohexanebutyric acid (diamond), and cyclohexanepentanoic acid (square). Vertical bars depict the standard error of the mean.

\section{Oil recovery}

We now consider the depletion of the average oil saturation in the cores. Here, we normalize the measured saturations by $S_{\text {oi }}$ to correct for minor differences in the latter between replicate experiments; in the discussion below this normalization is denoted by ${ }^{\wedge}$. Note that $\hat{S}_{\mathrm{o}}$ is simply the fractional volume of the original oil remaining in the core.

At the smallest $\theta_{\mathrm{o}}\left(=55^{\circ}\right)$, remaining oil saturation does not vary with time during sampling (Fig. 4, top), consistent with previous ${ }^{21-24}$ observations that residual state is established within $\tilde{t} \leq O(1)$ when the pore space is water wet everywhere. In contrast, when the oilcontacted surfaces are oil-wet, i.e., $\theta_{\mathrm{o}}>90^{\circ}$, $\hat{S}_{\text {o }}$ decreases with increasing $\widetilde{t}$ until it reaches a constant value. The constant value is interpreted as the residual oil saturation, $\hat{S}_{\text {or }}$.

The time required, in terms of pv of injected water, to establish residual saturation increases linearly with contact angle for $\theta_{\mathrm{o}}>90^{\circ}$ (Fig. 5$)^{\dagger}$, with a linear regression yielding (dotted line):

$$
\widetilde{t}_{\mathrm{c}}=-(108 \pm 8)+(1.07 \pm 0.06) \theta_{\mathrm{o}} ;
$$

the coefficient of determination is $r^{2}=0.99$. The monotonic increase of $\widetilde{t}_{\mathrm{c}}$ with $\theta_{\mathrm{o}}$ may be explained as follows. As discussed in the Introduction, extended oil depletion after water breakthrough is attributed to drainage via oil films. ${ }^{21,25}$ As $\theta_{0}$ increases, increasingly large (negative) capillary pressures are required for oil films to collapse ${ }^{29,30}$ and, accordingly, the films persist to increasingly later times (i.e., larger $\widetilde{t}_{\mathrm{c}}$ ).

Note that Eq. (2) cannot be extrapolated below $\theta_{\mathrm{o}} \leq 110^{\circ}$ since $\widetilde{t}_{\mathrm{c}}$ cannot take on negative values. Additional measurements are necessary to determine how $\widetilde{t}_{\mathrm{c}}$ varies below $\theta_{\mathrm{o}}=110^{\circ}$.

\footnotetext{
${ }^{\dagger}$ To avoid discontinuities in the model predictions, the residual state is assumed to have been reached at the value of $\widetilde{t}$ at which the best-fit power function intersects measured $\hat{S}_{\text {or }}$.
} 

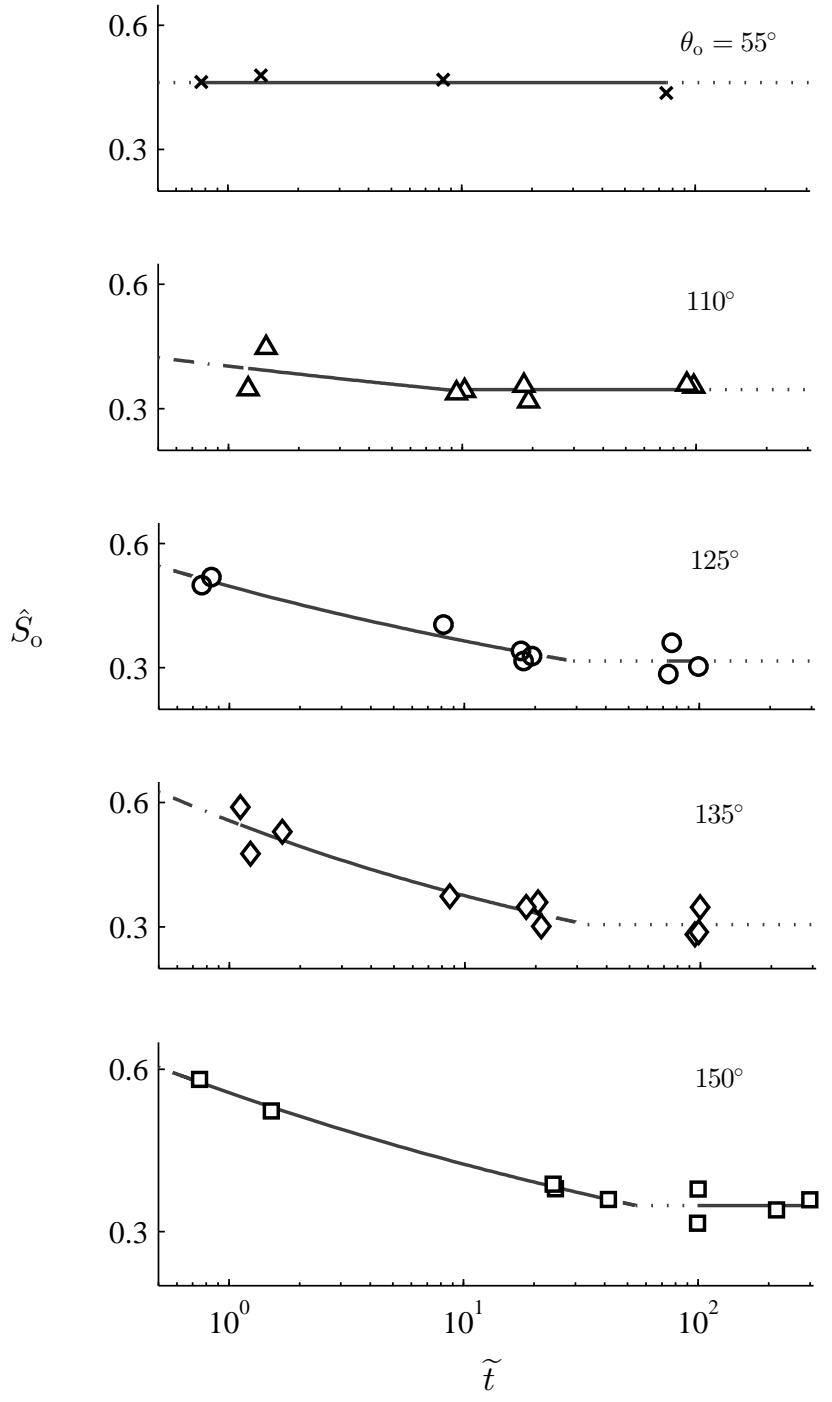

Figure 4: The evolution of remaining oil saturation during the waterflood. Solid lines are Eq. (3) fitted to the data; the dash-dotted and dotted lines are their extrapolation. Note that the abscissa are plotted on a logarithmic scale.

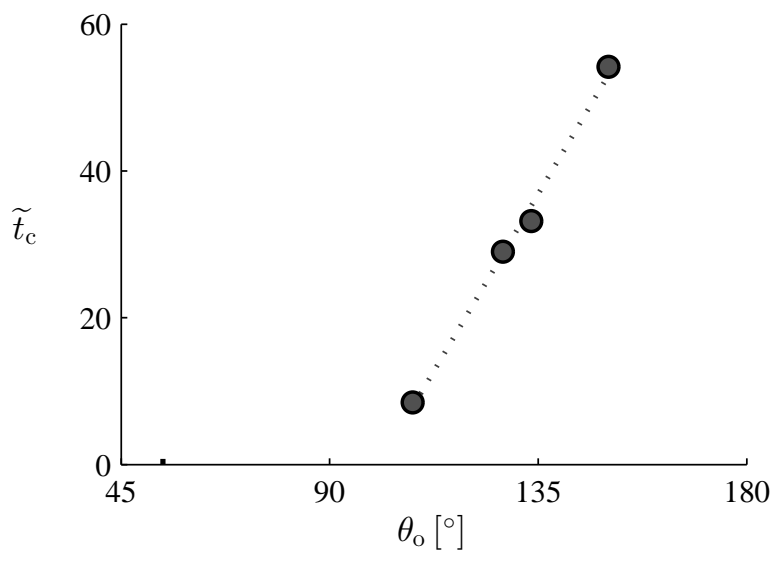

Figure 5: Pore volumes of flood water required to reach residual saturation as a function of contact angle. The dotted line is the line of best fit.

The depletion of oil saturation is well described by a power function of the form

$$
\hat{S}_{\mathrm{o}}=\left\{\begin{array}{ll}
\alpha \widetilde{t}^{-\beta}, & \widetilde{t} \leq \widetilde{t}_{\mathrm{c}} \\
\hat{S}_{\mathrm{or}}, & \widetilde{t}>\widetilde{t}_{\mathrm{c}}
\end{array},\right.
$$

where $\alpha$ and $\beta(>0)$ are best-fit coefficients in the least-squares sense to data at $\widetilde{t} \leq \widetilde{t}_{\mathrm{c}}$; the values of $\left(\alpha, \beta, \widetilde{t}_{\mathrm{c}}\right)$ are reported in Table 2 for each contact angle.

Coefficient $\alpha$, which is equivalent to the remaining oil saturation after $1 \mathrm{pv}$ of water injection, increases monotonically with $\theta_{\mathrm{o}}$ (Fig. 6a). This trend may be explained qualitatively as follows. Oil displacement within the first pore volume of water injection, i.e., up to and shortly after water breakthrough, is dominated by two mechanisms: ${ }^{39}$ piston-like displacement through the center of pores and snap-off in the narrow regions of the pore space. As contact angle increases, the former becomes increasingly favourable. ${ }^{39,40}$ At the same time, permeability to oil decreases while permeability to water increases ${ }^{15,32}$ and, accordingly, the efficiency of piston-like displacement decreases. Combined, the remaining oil saturation increases with increasing $\theta_{\mathrm{o}}$.

Coefficient $\beta$, which characterizes the rate of oil depletion from the rock after water breakthrough, increases from $\theta_{\mathrm{o}}=110^{\circ}$ to $135^{\circ}$, then decreases to $150^{\circ}$ (Fig. 6b). Oil displacement at later times is largely due to oil film drainage and 

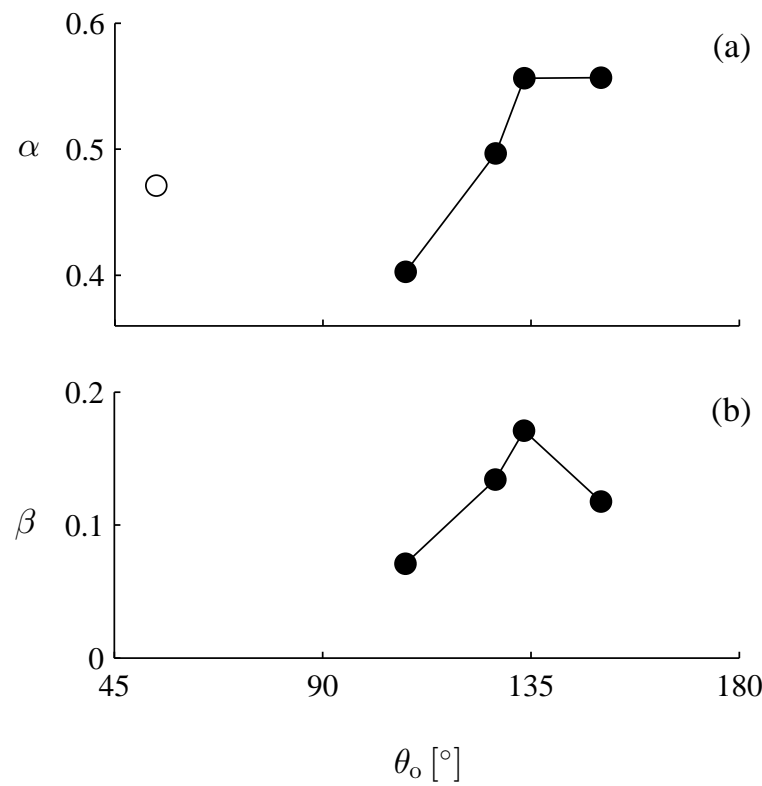

Figure 6: Remaining oil saturation after $1 \mathrm{pv}$ of water injection (a) and the rate of oil depletion (b) in the form of empirical coefficients for Eq. (3). Included for comparison is $\hat{S}_{\mathrm{o}}$ for $\theta_{\mathrm{o}}=55^{\circ}$ (open circle).

their eventual collapse. A possible explanation for the observed trend is that as $\theta_{0}$ increases, permeability to water increases, ${ }^{15,32}$ resulting in larger interstitial brine velocities in the center of pores and larger shear across the oil film. It seems plausible that larger shear will result in faster depletion of oil, and hence a larger $\beta$.

Using Eq. (3), remaining oil saturation can be interpolated to any time during the waterflood. Figure 7 presents remaining oil saturation as a function of contact angle at selected times. At early times, minimum remaining oil saturation (maximum recovery) occurs at $\theta_{\mathrm{o}}=110^{\circ}$ (e.g., + ). After $15 \mathrm{pv}$ of water injection minimum oil saturation occurs at $\theta_{\mathrm{o}}=125^{\circ}(*)$. Finally, after $25 \mathrm{pv}$ of injection (star), minimum saturation occurs at $135^{\circ}$. Combined, the data indicate that near-neutral wettability (of oilinvaded pores) is most favourable to recovery over the typical duration of a waterflood scheme (1 to $3 \mathrm{pv}$ ) but, if flow persists beyond this duration because of, e.g., tertiary EOR, decommissioning, geological $\mathrm{CO}_{2}$ storage, or groundwater flow, most oil is recovered under moderately oilwet conditions $\left(\theta_{\mathrm{o}} \approx 135^{\circ}\right)$.

As contact angle increases, the number of oil

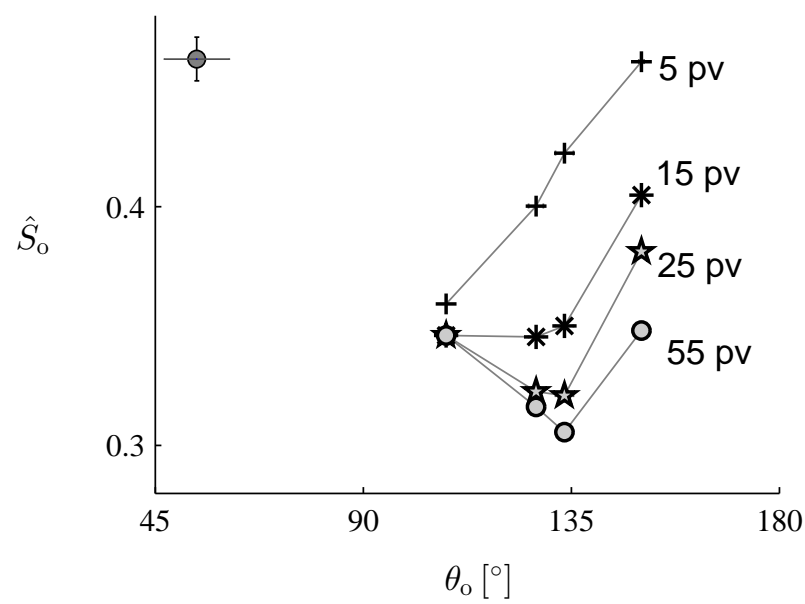

Figure 7: Remaining oil saturation at selected times as a function of contact angle.

films increase, which has two competing effects: the improved oil connectivity facilitates oil displacement and tends to reduce residual oil saturation, but the net volume of oil contained in the films increases. ${ }^{30}$ The non-monotonic trend in $\hat{S}_{\text {or }}$ suggests that the former dominates at near-neutral wettability, while the latter effect is more significant when the oil-contacted grain surfaces are more strongly oil-wetting.

\section{Conclusions}

Four organic acids were used to render Indiana limestone mixed-wet, with the degree of wettability alteration increasing with increasing alkyl group length of the acid. Under all mixed-wet conditions considered presently, remaining oil saturation decreases as waterflood progresses until it reaches a constant value. The approach to residual oil saturation is well described by a power law. It was found that the cumulative volume of water required to establish residual saturation increases linearly with increasing contact angle.

Over the life of a typical waterflood, optimal wettability for recovery (of oil-contacted surfaces) is near-neutral. However, beyond 15 pv of water injection, optimal wettability shifts gradually to more oil-wetting conditions, from $\theta_{0}=110^{\circ}$ to $125^{\circ}$ after $15 \mathrm{pv}$ of water injection, and then to $135^{\circ}$ after $25 \mathrm{pv}$ of in- 
Table 2: Summary of waterflood oil recovery measurements.

\begin{tabular}{lllllll}
\hline \hline coreflood porosity & $\begin{array}{l}k \\
{\left[\times 10^{-15} \mathrm{~m}^{2}\right]}\end{array}$ & $S_{\mathrm{oi}}$ & $\hat{S}_{\text {or }}$ & marker & $\hat{S}_{\mathrm{o}}(\widetilde{t})$ & $\widetilde{t}_{\mathrm{c}}$ \\
\hline
\end{tabular}

pure $n$-decane, $\theta_{\mathrm{o}}=(54 \pm 7)^{\circ}$

\begin{tabular}{lllllll}
\hline $\mathrm{M}$ & 0.152 & 8.7 & 0.86 & 0.45 & \multirow{2}{*}{$\mathrm{N} / \mathrm{A}$} & \multirow{2}{*}{$\mathrm{N} / \mathrm{A}$} \\
\hline $\mathrm{C}$ & 0.150 & 7.1 & 0.89 & 0.47 & & \\
\hline
\end{tabular}

$6.6 \times 10^{-2} \mathrm{M}$ cyclohexanecarboxylic acid, $\theta_{\mathrm{o}}=108^{\circ}$

\begin{tabular}{lllllll}
\hline $\mathrm{AC}$ & 0.149 & 5.9 & 0.92 & 0.34 & \multirow{2}{*}{$0.40 \widetilde{t}^{-0.071}$} & \multirow{2}{*}{8} \\
\hline $\mathrm{W}$ & 0.155 & 6.2 & 0.88 & 0.35 & & \\
\hline
\end{tabular}

$6.6 \times 10^{-2} \mathrm{M}$ cyclohexanepropionic acid, $\theta_{\mathrm{o}}=(127 \pm 2)^{\circ}$

\begin{tabular}{|c|c|c|c|c|c|c|}
\hline $\mathrm{O}$ & 0.143 & 3.8 & 0.89 & 0.30 & \multirow{3}{*}{$0.50 \widetilde{t}^{-0.13}$} & \multirow{3}{*}{29} \\
\hline$\overline{\mathrm{V}}$ & 0.154 & 8.4 & 0.86 & 0.28 & & \\
\hline $\bar{Y}$ & 0.153 & 7.4 & 0.85 & 0.35 & & \\
\hline
\end{tabular}

$6.6 \times 10^{-2} \mathrm{M}$ cyclohexanebutyric acid, $\theta_{\mathrm{o}}=(134 \pm 2)^{\circ}$

\begin{tabular}{llllllll}
\hline AF & 0.156 & 10.7 & 0.87 & 0.28 & & & \\
\cline { 1 - 5 } AH & 0.147 & 4.1 & 0.87 & 0.29 & $\diamond$ & $0.56 \widetilde{t}^{-0.17}$ & 33 \\
\hline AD & 0.139 & 2.0 & 0.88 & 0.35 & & & \\
\hline
\end{tabular}

$6.6 \times 10^{-2} \mathrm{M}$ cyclohexanepentanoic acid, $\theta_{\mathrm{o}}=(150 \pm 0.6)^{\circ}$

\begin{tabular}{lllllll}
\hline $\mathrm{TB} / \mathrm{I}^{a}$ & 0.133 & $1.64 \pm 0.03$ & 0.91 & 0.35 & \multirow{2}{*}{$0.56 \widetilde{t}^{-0.12}$} & \multirow{2}{*}{54} \\
\hline $\mathrm{TB} / \mathrm{J}^{a}$ & 0.139 & $1.46 \pm 0.02$ & 0.93 & 0.32 & & \\
\hline \hline
\end{tabular}

${ }^{a}$ Porosity, $k, S_{\mathrm{oi}}$, and selected $\hat{S}_{\mathrm{o}}$ were reported previously for these corefloods in Ref. 24. 
jection. These values are similar to the optimal contact angles reported for dolomite ${ }^{15}$ and silica sand, ${ }^{31}$ but is inconsistent with that reported for Torpedo sandstone. ${ }^{32}$ This disagreement suggests that the optimal wettability for recovery is strongly dependent on pore size distribution, grain roughness, or both. Further insight will require oil recovery measurements in geological media with systematically altered grain roughness and grain size distribution using, e.g., lab-on-a-chip methods. ${ }^{41}$

Acknowledgement This material includes work supported by a Society of Petrophysicists and Well Log Analysts (SPWLA) Foundation grant and a Aberdeen Formation Evaluation Society (AFES) scholarship. MC was supported by the University of Aberdeen College of Physical Sciences studentship. The authors gratefully acknowledge Renaud Dufour (Max Planck Institute for Dynamics and SelfOrganization) for the interfacial tension measurements, Amer Syed for his assistance in the design and assembly of the coreflood rigs, MSc student Luca Romanello and undergraduate student Matthew P. Wilkie for density and viscosity measurements, Colin Taylor for the mercury injection porosimetry measurements, Corex (UK) Ltd. for allowing LR access to their laboratory facilities during his work-based placement, and Roland Lenormand for his insightful comments and suggestions. The authors also thank the anonymous reviewer for their comments on the manuscript.

\section{Supporting Information Avail- able}

The following files are available free of charge. The supporting information is available free of charge on the ACS Publications website at DOI: xxxxxx.

- Details of experimental procedure for interfacial tension measurements.

- Details of experimental procedure for advancing contact angle measurements.
- Total acid number of the test oils (Table S1).

- Plot of advancing contact angle as a function of ageing time (Fig. S1).

- Equilibrium (long-time) advancing contact angle for each test oil (Table S2).

- Macroscopic capillary numbers for each waterflood (Table S3).

\section{References}

(1) Muggeridge, A.; Cockin, A.; Webb, K.; Frampton, H.; Collins, I.; Moulds, T.; Salino, P. Recovery rates, enhanced oil recovery and technological limits. Phil. Trans. R. Soc. A 2013, 372.

(2) Qiao, C.; Li, L.; Johns, R. T.; Xu, J. A mechanistic model for wettability alteration by chemically tuned waterflooding in carbonate reservoirs. Soc. Petrol. Eng. J. 2015, 20 .

(3) Yousef, A. A.; Al-Saleh, S.; Al-Kaabi, A.; Al-Jawfi, M. Laboratory investigation of the impact of injection-water salinity and ionic content on oil recovery from carbonate reservoirs. SPE Reserv. Eval. Eng. 2011, 14, 578-593.

(4) Yang, J.; Dong, Z.; Dong, M.; Yang, Z.; Lin, M.; Zhang, J.; Chen, C. Wettability alteration during low-salinity waterflooding and the relevance of divalent ions in this process. Energy Fuel 2016, 30, 7279 .

(5) Hilner, E.; Andersson, M. P.; Hassenkam, T.; Matthiesen, J.; Salino, P. A.; Stipp, S. L. S. The effect of ionic strength on oil adhesion in sandstone - the search for the low salinity mechanism. Scientific Reports 2015, 5 .

(6) Pedersen, N. R.; Hassenkam, T.; Ceccato, M.; Dalby, K. N.; Mogensen, K.; Stipp, S. L. S. Low salinity effect at pore 
scale: probing wettability changes in Middle East limestone. Energy Fuel 2016, 30, 3768-3775.

(7) Mohan, K.; Gupta, R.; Mohanty, K. K. Wettability altering secondary oil recovery in carbonate rocks. Energy Fuels 2011, 25, 3966-3973.

(8) Kathel, P.; Mohanty, K. K. Wettability alteration in a tight oil reservoir. Energy Fuel 2013, 27, 6460-6468.

(9) Benner, F. C.; Bartell, F. E. The effect of polar impurities upon capillary and surface phenomena in petroleum production. 22nd Annual Meeting. San Francisco, CA, 1941.

(10) Rezaei Gomari, K. A.; Denoyel, R.; Hamouda, A. A. Wettability of calcite and mica modified by different long-chain fatty acids (C18 acids). J. Colloid Interf. Sci. 2006, 297, $470-479$.

(11) Roosta, A.; Escrochi, M.; Varzandeh, F.; Khatibi, J.; Ayatollahi, S.; Shafiei, M. Investigating the mechanism of thermally induced wettability alteration. Proc., SPE Middle East Oil \& Gas Show and Conference, 15-18 Mar. Bahrain, 2009.

(12) Treiber, L. E.; Archer, D. L.; Owens, W. W. A laboratory evaluation of the wettability of fifty oil-producing reservoirs. Soc. Petrol. Eng. J. 1972, 12, $531-540$.

(13) Xie, X.; Morrow, N. R.; Buckley, J. S. Crude oil/brine contact angles on quartz glass. Proc., International Symposium of the Society of Core Analysts, 7-10 Sept. Calgary, Alberta, Canada, 1997.

(14) Wu, Y.; Shuler, P. J.; Blanco, M.; Tang, Y.; Goddard III, W. A. An experimental study of wetting behavior and surfactant EOR in carbonates with model compounds. Soc. Petrol. Eng. J. 2008, 13, $26-34$.
(15) Morrow, N. R.; Cram, P. J.; McCaffery, F. G. Displacement studies in dolomite with wettability control by octanoic acid. Soc. Petrol. Eng. J. 1973, 13, 221-232.

(16) Wagner, O. R.; Leach, R. O. Improving oil displacement efficiency by wettability adjustment. Petrol. Trans. AIME 1959, $216,65-72$.

(17) Hamouda, A. A.; Rezaei Gomari, K. A. Influence of temperature on wettability alteration of carbonate reservoirs. Proc., SPE Annual Technical Conference and Exhibition, 22-26 Apr. Tulsa, Oklahoma, 2006.

(18) Jerauld, G. R.; Rathmell, J. J. Wettability and relative permeability of Prudhoe Bay: a case study in mixed-wet reservoirs. $S P E$ Reservoir Eng. 1997, 12, 58-65.

(19) Barranco, F. T.; Dawson, H. E. Influence of aqueous $\mathrm{pH}$ on the interfacial properties of coal tar. Environ. Sci. Technol. 1999, 33, 1598-1603.

(20) Dwarakanath, V.; Jackson, R. E.; Pope, G. A. Influence of wettability on the recovery of NAPLs from alluvium. Environ. Sci. Tech. 2002, 36, 227-231.

(21) Salathiel, R. A. Oil recovery by surface film drainage in mixed-wettability rocks. Soc. Petrol. Eng. J. 1973, 25, 1216-1224.

(22) Mungan, N. Interfacial effects in immiscible liquid-liquid displacement in porous media. Soc. Petrol. Eng. J. 1966, 6, $247-$ 253.

(23) Tanino, Y.; Blunt, M. J. Capillary trapping in sandstones and carbonates: dependence on pore structure. Water Resour. Res. 2012, 48 .

(24) Tanino, Y.; Blunt, M. J. Laboratory investigation of capillary trapping under mixed-wet conditions. Water Resour. Res. 2013, 49, 4311-4319. 
(25) Kovscek, A. R.; Wong, H.; Radke, C. J. A pore-level scenario for the development of mixed wettability in oil reservoirs. AIChE J. 1993, 39, $1072-1085$.

(26) Graue, A.; Viksund, B. G.; Eilertsen, T.; Moe, R. Systematic wettability alteration by aging sandstone and carbonate rock in crude oil. J. Petrol. Sci. Eng. 1999, 24, 85 -97 .

(27) Jadhunandan, P. P.; Morrow, N. R. Effect of wettability on waterflood recovery for crude-oil/brine/rock systems. SPE Reservoir Eng. 1995, 10, 40-46.

(28) Anggraini, L. Buckley-Leverett Analysis of Waterflood Oil Recovery from MixedWet Rock. M.Sc. thesis, University of Aberdeen, Scotland, UK, 2013.

(29) Blunt, M. J. Physically-based network modeling of multiphase flow in intermediate-wet porous media. J. Petrol. Sci. Eng. 1998, 20, 117-125.

(30) Ryazanov, A. V.; van Dijke, M. I. J.; Sorbie, K. S. Two-phase pore-network modelling: existence of oil layers during water invasion. Transp. Porous Media 2009, 80, 79-99.

(31) Kennedy, H. T.; Burja, E. O.; Boykin, R. S. An investigation of the effects of wettability on oil recovery by water flooding. J. Phys. Chem. 1955, 59, 867-869.

(32) Owens, W. W.; Archer, D. L. The effect of rock wettability on oil-water relative permeability relationships. J. Petrol. Technol. 1971, 23, 873-878.

(33) Ethington, E. F. Interfacial contact angle measurements of water, mercury, and 20 organic liquids on quartz, calcite, biotite, and Ca-montmorillonite substrates; Open-File Report 90-409, 1990.

(34) Good, R. J.; Mikhail, R. S. The contact angle in mercury intrusion porosimetry. Powder Technol. 1981, 29, 53-62.
(35) Abell, A. B.; Willis, K. L.; Lange, D. A. Mercury intrusion porosimetry and image analysis of cement-based materials. J. Colloid Interf. Sci. 1999, 211, 39 - 44.

(36) ASTM, Standard Test Method for Acid and Base Number by Color-Indicator Titration D974-12. 2012.

(37) Tanino, Y.; Akamairo, B.; Christensen, M.; Bowden, S. A. Impact of displacement rate on waterflood oil recovery under mixed-wet conditions. Proc., International Symposium of the Society of Core Analysts. St. John's Newfoundland and Labrador, Canada, 2015.

(38) Mungan, N. Role of wettability and interfacial tension in water flooding. Soc. Petrol. Eng. J. 1964, 4, 115-123.

(39) Lenormand, R.; Zarcone, C.; Sarr, A. Mechanisms of the displacement of one fluid by another in a network of capillary ducts. J. Fluid Mech. 1983, 135, 337-353.

(40) Valvatne, P. H.; Blunt, M. J. Predictive pore-scale modeling of two-phase flow in mixed wet media. Water Resour. Res. 2004, 40, W07406.

(41) Bowden, S. A.; Tanino, Y.; Akamairo, B.; Christensen, M. Mineralogically heterogeneous rock in a chip: assembly, examples, and applications. Lab Chip 2016, 46774681. 